\title{
Investigation of the Effects of Rice Husk and Rice Straw on the Properties of Lightweight Fibrecrete Blocks
}

\author{
Abaza Leo, Kyakula Michael \\ Department of Civil and Environmental Engineering, Kyambogo University, Kampala, Uganda \\ Email address: \\ leoabaza5@gmail.com (A. Leo), mkyakula@kyu.ac.ug (K. Michael)
}

\section{To cite this article:}

Abaza Leo, Kyakula Michael. Investigation of the Effects of Rice Husk and Rice Straw on the Properties of Lightweight Fibrecrete Blocks. Journal of Civil, Construction and Environmental Engineering. Vol. 6, No. 5, 2021, pp. 135-143. doi: 10.11648/j.jccee.20210605.12

Received: September 3, 2021; Accepted: October 8, 2021; Published: October 28, 2021

\begin{abstract}
Uganda's progress towards achieving sustainable growth is curtailed by poor and limited infrastructure, over $60 \%$ of the urban population live in slums with poor quality housing and hygiene, $44 \%$ of the households sleep in one room, the situation is more critical in Kampala where about 70\% sleep in one room. About $67 \%$ of Ugandans live in dwellings with brick walls while $28 \%$ live in dwellings of mud walls reinforced with timber poles. Over $90 \%$ of framed structure in Uganda are built from reinforced concrete structures with bricks or block infill walls that are heavy thus influencing the type and size of structural members hence its cost. This research focused on use of Rice Husks (RH) and Rice Straws (RS) in lightweight fibrecrete blocks for benefit of their reduced weight, reducing environmental pollution, low processing energy, and availability at modest cost. In this research, the fibres were alkali-treated using sodium hydroxide solution prepared by dissolving $15 \mathrm{~g}$ of sodium hydroxide pellets in 1 liter of water heated at $100^{\circ} \mathrm{C}$ for 60 minutes. This was aimed at increasing surface roughness, expose cellulose to fibre surface, improve fibre/matrix adhesion, eliminate weak boundary layers and remove superficial lignin layer. The alkali treated fibres were used to prepare one hundred twenty one (121) fibrecrete blocks of RH and RS with varying proportions of $0 \%$, $10 \%, 20 \%, 30 \%, 40 \%$, and $50 \%$ fibre and tested for their density, compressive strength, water absorption, thermal conductivity, fire resistances and microstructure. The densities of lightweight fibrecrete blocks ranged between $1947-1485 \mathrm{~kg} / \mathrm{m}^{3}$ with a reduction of $7.9-30.5 \%$ compared to aggregate blocks of $2138 \mathrm{~kg} / \mathrm{m}^{3}$ density. Compressive strength of the blocks varied between $1.53-5.36 \mathrm{~N} / \mathrm{mm}^{2}$ and $1.28-3.48 \mathrm{~N} / \mathrm{mm}^{2}$ for RH and RS blocks respectively with control block having compressive strength of $7.2 \mathrm{~N} / \mathrm{mm}^{2}$ at 28 days. Compressive strength loss in the lightweight fibrecrete blocks tested for fire resistance ranged between 10.7-34.3\% and 6.8-73.7\% for RH and RS-blocks respectively while the water absorption ranged between 5.8-7.8\% for RH and 6.4-11.3\% for RS blocks and 3.6\% for aggregate blocks. Thermal conductivity was improved by 13.4-64.8\%. The researcher concluded that, RH-40 and RS-20 blocks have the most appropriate proportions for lightweight fibrecrete blocks. This would reduce Environmental degradation, utilize agricultural waste, increase the income of the farmers, reduce construction cost due to reduced density of fibrecrete blocks, and increase thermal insulation hence thermal comfort of the occupants.
\end{abstract}

Keywords: Rice Husk Blocks, Rice Straw Blocks, Fibrecrete Blocks, Lightweight Blocks, Properties of Blocks

\section{Introduction}

Uganda is one of the Developing Countries with a moderate tropical climate and a high rate of low-income housing [1] with agriculture as the main stay of the economy employing $73 \%$ of the labor force and contributing $21 \%$ to the GDP [2].

Uganda's progress towards achieving inclusive sustainable growth is curtailed by poor and limited infrastructure. Around $38 \%$ of Uganda's Population live below the International poverty line and over $60 \%$ of the Ugandan urban population live in slums with poor quality housing and hygiene conditions [3].

Uganda needs to industrialize its construction sector as a way of improving the supply of housing to its citizens. This industrialization includes developing and standardizing local materials. As observed by Alinaitwe et al. [4] "Industrialization assumes that most materials are standardised that materials and components can be manufactured in several places but they can fit in the final product without discrimination based on origin".

In Uganda, the commonest materials used for constructing walls are mud and timber poles, bricks and blocks. Overall, 
two thirds of the households in Uganda live in dwellings with brick walls $(67 \%)$ while $28 \%$ of household dwellings have walls made of mud and timber poles [5]. Brick masonry with embodied Energy at 580.2 GJ consumes highest energy in comparison to all other common masonry options [6].

The current situation of using burnt bricks for walling has negatively affected the environment contributing to issues such as deforestation, desertification, air pollution, excessive agricultural soil extraction, food and fuel crisis, and health issues in the country [7]. It is obvious that the current situation could lead to social and environmental disaster if no positive action is put in place to improve the conditions.

The envisaged option considered to replace fired brick walls, is a combination of revised earth technologies. This option is rooted in the fact that earth technologies have been a reliable and consistent walling choice in Africa for centuries surprisingly; today this has taken a back seat since cement blocks and fired clay bricks are regarded as symbols of modernity and progress even in the most remote communities [7].

Uganda is experiencing rapid deforestation, as indicated by the declining forest area from 24 percent to 18 percent, between 1990 and 2005 due to unsustainable harvesting [8]. The National Development Plan also reported that the forest cover has gone down from 4.9 million hectares in 1990 to 3.6 million hectares in 2015, representing a $27 \%$ drop [9].

Development of local building materials in a sustainable way has a number of economic, environmental and health merits. It reduces the house production costs, a very important aspect for the successful access to decent housing by low-income earners; it protects the eco-system, and it contributes to the improvement of the living environment of a given community through the practical use of local resources.

Indigenous constructions have the potential of supporting sustainable development of decent, low-cost housing through the use of locally available building materials and designs, that require little input in terms of labor, technical knowledge and skills, further facilitating more efficient energy use and energy conservation systems. In exploiting this potential, it is imperative to do so in a sustainable manner to ensure that, the finite resources are used rationally.

Affordable housing for all income levels is a present need [10]. The use of local building materials has the potential of increasing access to decent housing through reduced housing costs, especially for low-income earners. Use of local materials, if rationally implemented, also contributes in mitigating negative impacts of climate change [11].

Enhancement of engineering properties of blocks with agricultural waste fibres has potential to produce more robust and resilient homes for some poorest communities in Less Economically Developed Countries [12].

The increase in popularity of using environmentally friendly, low cost and lightweight construction materials in building industry has brought about the need to investigate the effects of rice husk and rice straw on the properties of lightweight fibrecrete blocks to benefit the environment as well as maintaining the material requirements.

\subsection{Problem Statement}

Sustainability is one of the focuses of recent International Housing Development Strategies. At present, vast majority of housing units are reinforced concrete structures with either bricks or concrete block infill walls [13].

However, most materials used for the construction of these infill walls are heavy thus influencing the type and size of foundation and other structural members by their dead loads [14] hence an increased cost of construction.

Lightweight building materials are local abundantly available, their efficient utilization in developing decent housing is still a challenge as they are largely unprocessed, underdeveloped and un-standardised, limiting their potential. These factors have led to inefficient and unfavorable exploitation of these materials thus manifesting into low acceptability, unstable cost of local building materials thus putting their sustainability in question.

Concrete masonry incorporated with lightweight material could contribute to a significant weight reduction ranging from $10 \%$ to $40 \%$ compared to the masonry blocks using normal weigh concrete blocks [15]. Uganda produces about 49,200 tons of rice husks and an estimated $(182,040-1,008,600)$ tons of rice straws per year, these rice husks and straws are not properly utilized as they are either thrown away or burned in open air.

This research aimed at investigating reduction of the weight of blocks by use of rice husks and rice straws; for the benefit of masonry construction, lighter building materials, cost saving, enhancement of environmentally friendly and sustainable design.

\subsection{Objectives of the Study}

The main objective of the study was to investigate the effects of rice husks and rice straws on the properties of 'lightweight fibrecrete blocks'. This was guided be the following objectives:

1. To establish the mix proportions of constituent materials suitable for production of 'lightweight fibrecrete blocks' using rice husks and rice straws.

2. To determine the density, water absorption, thermal conductivity, fire resistance and compressive strength of 'lightweight fibrecrete blocks' produced using rice husks and rice straws.

3. To Establish how the Microstructure of 'lightweight fibrecrete blocks' produced using rice husks and rice straws influences its properties.

\section{Literature Review}

\subsection{Housing in Uganda}

Housing is one of the basic human needs that has a profound impact on health and welfare of an individual. The Universal Declaration of Human Rights of 1948 recognizes the right to housing as an important component of human rights. Other international declarations and charters such as the International Covenant on Economic, 
Social and cultural Rights of 1966, Agenda 21 of 1992, the Istanbul Declaration and Habitat Agenda of 1996 recognizes the right to housing.

Similarly, the African Charter on Human and People's Rights (1986), the East African Community Treaty and Goal 11 of Sustainable Development Goals (SDG) have further reaffirmed the importance of the right to decent housing. The Government of Uganda too recognizes the strategic social and economic importance of housing in the National economy and, particularly, to the Socio Economic Transformation of the Country as highlighted in Vision 2040 [7].

About six (6) million Ugandan Families live in 4.5 million residential units, which means an average occupancy density of around 1.3 families per dwelling. The conditions are more critical for slum residents, the majority of whom live in single-room rented properties [16]. The average number of occupants in most houses, particularly in urban areas, is more than the International Standards of two persons per room with National average Household size of 4.9 and the average number of Occupants per room of 2.9 person [2].

According to the Uganda National Household Survey $2009 / 2010,33 \%$ of Ugandan families use two rooms and $44 \%$ use only one room for sleeping [2]. The situation is more critical in Kampala where around $70 \%$ of households use only one room for sleeping. The number of rooms used for sleeping and the number of persons sleeping per room are proxies to indicate the extent of crowding in households, Overcrowding is a major issue in Uganda, and it endangers the health, safety and welfare of the occupants. Overcrowding, for instance, increases the risk of contracting infectious diseases such as Covid-19, tuberculosis, measles and meningitis.

Uganda has a deficit of 2.1 million housing units, growing at rate of 200,000 units a year; in 2030, the deficit is expected to reach 3 million units. This on the accounts of the rapid urbanization rate and high population growth rates of 3.2 percent per annum [17]. This rate continues to affect the country's housing sectors. Although more housing units are needed, construction costs are still high as reflected by the rising construction sector indices. The demand for low cost sustainable building materials is growing as social, economic and environmental issues evolve in today's society. The urgent need to develop suitable and affordable housing is born because of the fact that over one billion people in the world most of whom live in developing countries either are homeless or live in very poor housing [10].

The demand for quality building material in Uganda is on the rise due to the current boom in the construction industry as reported in the National Population and Housing Census of 2016 by the Uganda Bureau of Statistics, increased population led to increased demand for housing.

\subsection{Natural Fibres}

The chemical composition and structure of natural fibres are quite complex; most plant fibres are composed of Cellulose, Hemicelluloses, Lignin, Pectin, Waxes, and a few water-soluble compounds $[18,19]$. The presence of Cellulose that is hydrophilic in nature affects the interfacial bonding between the cement matrix and the fibres because the matrix is hydrophobic [19].

\subsection{Advantage of Natural Fibres}

The use of natural fibres to develop new composites provides several advantages such as lightness, better rheological behavior, and good flexural and compressive strength, modulus of crack, renewability and low environmental impact related to their production [20]. The applications of natural fibre composites as construction material in creating built environment holds the enormous potential and are critical for achieving sustainable development [21]. The renewable character, low processing energy in the case of chopped natural fibres makes it good for composites [22]. Natural fibres are lightweight thus used for making lightweight composites materials [19].

\subsection{Challenges with Plant Fibre Cementitious Composites}

High variability of physical and mechanical properties of plant fibres due to variation in their chemical structure and composition, such as cellulose content, degree of polymerization, orientation of molecular chains, crystallinity $[23,24]$. These parameters are highly dependent on the growth conditions of the plant and fibre extraction methods [18]. Fibres extracted from different parts of the plants or grown in different locations and weather conditions present huge variability in their length, cross-sectional area, and mechanical properties [25].

The high moisture absorption of plant fibres leads to swelling due to absorption of moisture and shrink when moisture is removed due to dry atmosphere and elevated temperatures. The frequent swelling, shrinking phenomena leads to formation of cracks hence reduced mechanical performance and durability of cementitious composites. During mixing with cementitious materials they absorb considerable amount of water and reduce the water required for cement hydration hence reduced degree of cement hydration thus poor mechanical performance of cementitious composites [24].

Due to the hydrophilic nature of the fibres, the interface formed between plant fibres and hydrophobic matrices is very weak $[19,21]$. However, the interface of plant fibres with hydrophilic matrices can be better because of interfacial hydrogen bonds; the high moisture absorption of plant fibres leads to breakage of interfacial hydrogen bonds occurs in the interfacial region, weakening the fibre/matrix bonding [26]. To improve the adhesion between fibres and matrix pre-treatment can be done using hydroxyl groups that gets the fibre activated or new materials added to effectively interlock with the matrix [21]. Poor interface bond between the plant fibres and different matrices in the fibre composites leads to inferior load transfer between fibre and matrix hence lower mechanical performance [25].

\subsection{Fibre Surface Modification}

Pre-treatment of fibres are classified into three major 
techniques. These include mechanical treatment, thermal treatment and chemical treatment [18, 22]. Chemical treatments are aimed at improving the fibre/matrix adhesion by increasing the surface roughness of the natural fibers by cleaning the fibre surface from impurities and disrupting the water absorption process through the layer of $\mathrm{OH}$ groups in fibre [27]. The chemical composition of coupling agents allows them to react with the fibre surface and forms a bridge of chemical bonds between the fibre and matrix to increase the fibre/matrix adhesion [23]. The most used treatment is alkaline treatment owing to its cost effectiveness [28]. Alkali treatment leads to the creation of new functional groups on fibres surface [29]. This could provide a thin layer on fibres surface that could resist the effect of alkali environment; however, treating fibres with chemical solution reduces the effect of alkali attack and overcomes the weak bond between the fibre and the cement matrix by formation of a rough fibre surface [30].

Alkali treatment increases surface roughness resulting in better mechanical bonding and the amount of cellulose exposed on the fibre surface thus increasing the number of possible reaction sites and allows better fibre wetting [31].

Fibre- $\mathrm{OH}+\mathrm{NaOH} \rightarrow$ Fibre-O-Na+ $+\mathrm{H}_{2} \mathrm{O}$

\section{Materials and Methods}

\subsection{Rice Straws and Rice Husks}

The straws were collected from Kehong Uganda Industrial Development Limited located in Luwero District. The straws were cut into $5-10 \mathrm{~cm}$ in length, the main aim of cutting the straws $5-10 \mathrm{~cm}$ was to make them as small as possible for easy mixing. The cut straws were boiled in a solution of sodium hydroxide prepared by dissolving $15 \mathrm{~g}$ of sodium hydroxide pellets in 1 (one) litre of water at about $100^{\circ} \mathrm{C}$ for 60 minutes and cleaned in water to remove excess or unreacted Sodium Hydroxide from the surface of the rice straws. Water squeezed out of the rice straws; the sample was then dried in sunshine.

The rice husks were collected from rice mills in Masindi District. The husks boiled in a solution of sodium hydroxide prepared by dissolving $15 \mathrm{~g}$ of sodium hydroxide pellets in 1 (one) litre of water at about $100^{\circ} \mathrm{C}$ for 60 minutes and then cleaned in water to remove excess or unreacted Sodium Hydroxide from the surface of the rice husks. Water squeezed out of the husks; the sample was then dried in sunshine.

Alkali treatment leads to the creation of new functional groups on fibres surface [29]. This treatment increases surface roughness, resulting in better mechanical interlocking; it also increases the amount of cellulose exposed on the fibre surface, thus increasing the number of possible reaction sites [32].

\subsection{Preparation of Blocks}

In the manufacture of the blocks, Hand mixing was employed and the materials were turned over a number of times until an even color and consistency were attained. Water added to the mix and the mix further turned over to secure adhesion.

The block were cast in moulds of internal diameter $400 \mathrm{~mm}$ $\mathrm{x} 150 \mathrm{~mm} \times 200 \mathrm{~mm}$ based on the common dimensions in Ugandan market and then allowed to set. The blocks were left on pallets under cover in separate rows, one block high and with a space between two blocks for the curing period of 28 days. They were kept wet during the curing period by sprinkling water on the blocks daily.

One hundred twenty one (121) blocks were prepared for the research as shown in Table 1. The blocks were tested for their Compressive Strength, Density, Water absorption, Fire Resistance, Thermal Conductivity and Micro Structure examination using Scanning Electron Microscope (SEM).

Table 1. Schedule of the blocks.

\begin{tabular}{lll}
\hline Sample Code & $\begin{array}{l}\text { Mix proportions by weight } \\
\text { Cement: Sand: Fibre }\end{array}$ & $\begin{array}{l}\text { No. of } \\
\text { blocks }\end{array}$ \\
\hline CT-0 & $1: 4: 0$ & 11 \\
RS-10 & $1: 3.9: 0.1$ & 11 \\
RH-10 & $1: 3.9: 0.1$ & 11 \\
RS-20 & $1: 3.8: 0.2$ & 11 \\
RH-20 & $1: 3.8: 0.2$ & 11 \\
RS-30 & $1: 3.7: 0.3$ & 11 \\
RH-30 & $1: 3.7: 0.3$ & 11 \\
RS-40 & $1: 3.6: 0.4$ & 11 \\
RH-40 & $1: 3.6: 0.4$ & 11 \\
RS-50 & $1: 3.5: 0.5$ & 11 \\
RH-50 & $1: 3.5: 0.5$ & 11 \\
\hline
\end{tabular}

\subsection{Density Determination}

The Density of each block was calculated by determining the weight $(\mathrm{Kg})$ and volume $\left(\mathrm{m}^{3}\right)$ by measuring the length, width and thickness. The Density of the blocks was calculated as weight of the block unit divided by the dimensional volume according to BS EN 772-4:1998.

$$
\text { Density }=\frac{\text { Mass of Block }(\mathrm{kg})}{\text { Dimensional Volume of Block }(\mathrm{m} 3)}
$$

\subsection{Compressive Strength Determination}

Compressive strength of the blocks tested to determine the maximum load the blocks can withstand. The compressive strength of the blocks was determined according to BS EN12390-3:2019, employing a Universal Testing Machine (UTM) as shown in Figure 1.

The compressive strength for the blocks was determined by crushing three blocks per mix at 7 and 28 days respectively. The blocks were placed on the plate of compressive testing apparatus with two plates placed above and below each block to distribute the load evenly; each block of nominal dimension $400 \times 150 \times 200 \mathrm{~mm}$ was weighed and aligned on the Universal Testing Machine (UTM). This was followed by gradual application of load until failure. Maximum applied load was recorded and used to calculate compressive strength. 


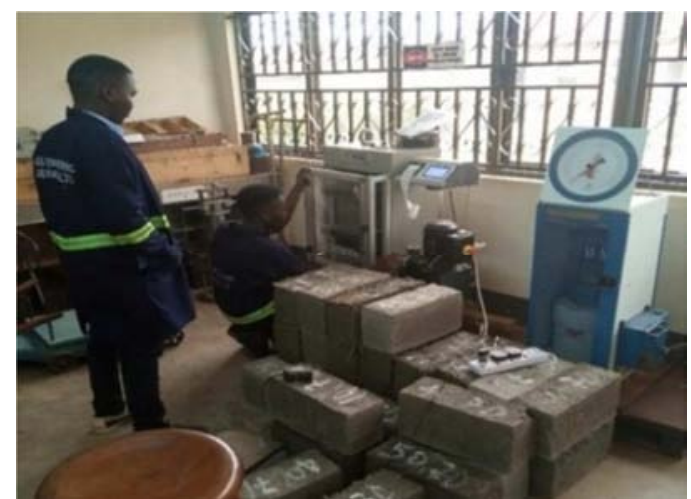

Figure 1. Determination of compressive strength of the blocks.

Maximum Compressive Strength of individual Blocks evaluated by the equation (3)

$$
\text { Compressive Strength }=\frac{\text { Maximum load at failure }}{\text { Contact area }}\left(\mathrm{N} / \mathrm{mm}^{2}\right)
$$

\subsection{Water Absorption Determination}

Water absorption test is a common method of determining water resistance. The test procedure as per BS 1881-122:2011+A1:2020 was used to measure the amount of water that penetrates into block samples when submersed in clean water at room temperature.

The water absorption was determined by measuring the amount of water absorbed by a dried sample that had been immersed in water for a specified period ( 24 hours).

The blocks were dried in a ventilated oven at $100-105^{\circ} \mathrm{C}$ for 24 hours, the blocks were weighed (Md). The blocks were then fully immersed in a water bath, and left there for 24 hours. The blocks were removed from the water bath after 24 hours and wiped until dry. The saturated and surface dry blocks immediately weighed $(M \mathrm{w})$.

The water absorption of blocks obtained using equation (4).

$$
\text { Water Absorption (\%) }=\frac{M w-M d}{M d} \times 100
$$

Where,

$\mathrm{Mw}(\mathrm{g})$ is mass of wet blocks

$\mathrm{Md}(\mathrm{g})$ is mass of blocks after drying.

The results were expressed as a percentage of the original dry mass of the specimen to the nearest $0.1 \%$ of the dry mass.

\subsection{Thermal Conductivity Determination}

The thermal conductivity of the blocks were determined using Hot-wire method. The hot-wire method which is a transient technique that measures temperature rise at a known distance from a linear heat source (i.e. hot wire, usually platinum or tantalum) embedded in the test sample.

Thermal conductivity test was performed using a Quick Thermal Conductivity Meter QTM- 500 shown in Figure 2. The QTM-500 instrument used for measuring the thermal conductivity has a limiting measuring range of $0.023 \mathrm{w} /(\mathrm{mk})$ to $12 \mathrm{w} /(\mathrm{mk})$ with a precision and reproducibility of $\pm 5 \%$ and $\pm 3 \%$ on reading values respectively. The minimum sample size required for testing was $100 \times 50$ × $20 \mathrm{~mm}$ thickness.
Thermal conductivity of the fibrecrete blocks was tested at room temperature.

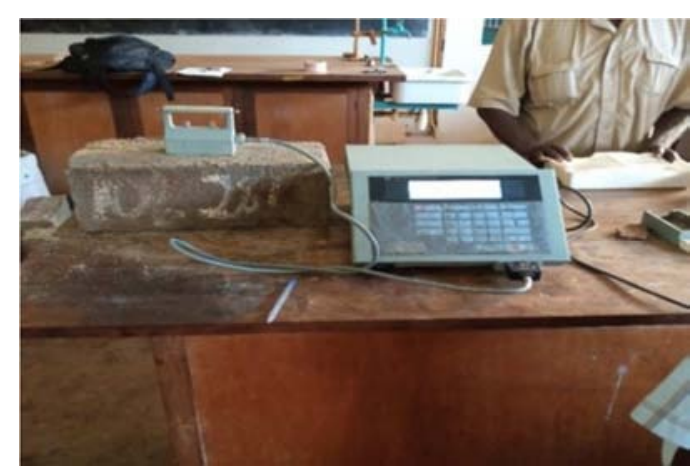

Figure 2. Determination of thermal conductivity of the blocks.

\subsection{Fire Resistance Determination}

The fire resistance of concrete blocks was tested at 28 days of curing. The blocks were subjected to a temperature of $500^{\circ} \mathrm{C}$ for one hour in a furnace. Then, the samples cooled at room temperature in open-air condition for twenty-four 'hours The residual compressive of the blocks determined according to BS EN 12390-3:2019 employing a Universal Testing Machine (UTM).

\subsection{Determination of Microstructure}

Scanning electron microscopy (SEM) was conducted to determine whether gaps exist at the peripheral of the fibres in the specimen blocks. Selected blocks from each mix proportion were cut to expose the internal parts for analysis with scanning electron microscope.

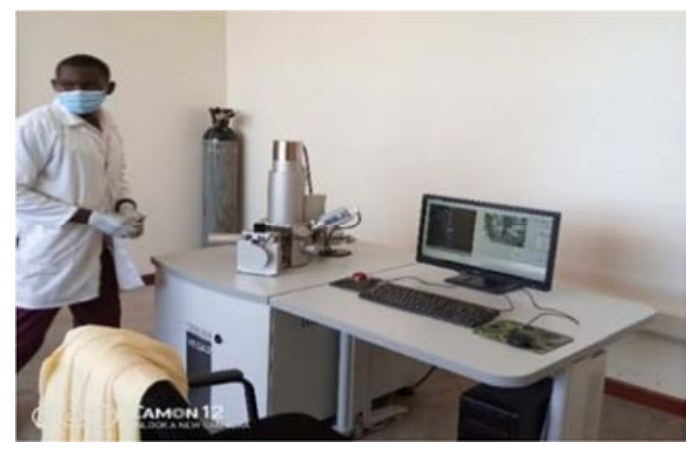

Figure 3. Determination of microstructure of the blocks.

The Scanning Electronic Microscope (SEM) as shown in Figure 3 is controlled via personal computer, with a power dispersing attachment for elemental microanalysis and vacuum processing of samples. Perfect optical properties, not flickering numeral image of excellent quality at high speed scanning.

Scanning Electronic Microscope (SEM) analysis running at $10 \mathrm{kv}$ was used to study the microstructure of the blocks. The microstructure of the blocks displayed on the monitor, which was connected to the machine at different magnifications ranging from 4-100000 and at different view fields. 


\section{Results and Discussion}

\subsection{Density of Blocks}

The densities of RH blocks varied between 1497-1970 $\mathrm{Kg} / \mathrm{m}^{3}$ while the densities of RS blocks varied between $1485-1947 \mathrm{Kg} / \mathrm{m}^{3}$ and the aggregate blocks have average density of $2138 \mathrm{Kg} / \mathrm{m}^{3}$ at 28 days. The results as shown in Figure 4 indicate a decrease in the densities of fibrecrete blocks as the proportion of rice husk and rice straw increases.

The reduction in the densities of fibrecrete blocks varied from 7.9 -30\% for RH-blocks, and 8.9-30.5\% for RS-blocks.

According to (Uganda standard specifications, 2018) solid concrete blocks are grouped into three density grades as; Grade A, density $\geq 2100 \mathrm{Kg} / \mathrm{m}^{3}$; Grade B, $1681 \mathrm{Kg} / \mathrm{m}^{3} \leq$ density $\leq 2099 \mathrm{Kg} / \mathrm{m}^{3}$ and Grade C, density $\leq 1680 \mathrm{Kg} / \mathrm{m}^{3}$. As per Figure 4, blocks of RH-10 to RH-30 and RS-10 to RS-30 have densities between $1680-2099 \mathrm{Kg} / \mathrm{m}^{3}$ hence are Grade B block. Blocks of RH-40 to RH-50 and RS-40 to RS- 50 have densities $\leq 1680 \mathrm{Kg} / \mathrm{m}^{3}$ hence they belong to Grade $\mathrm{C}$ blocks.

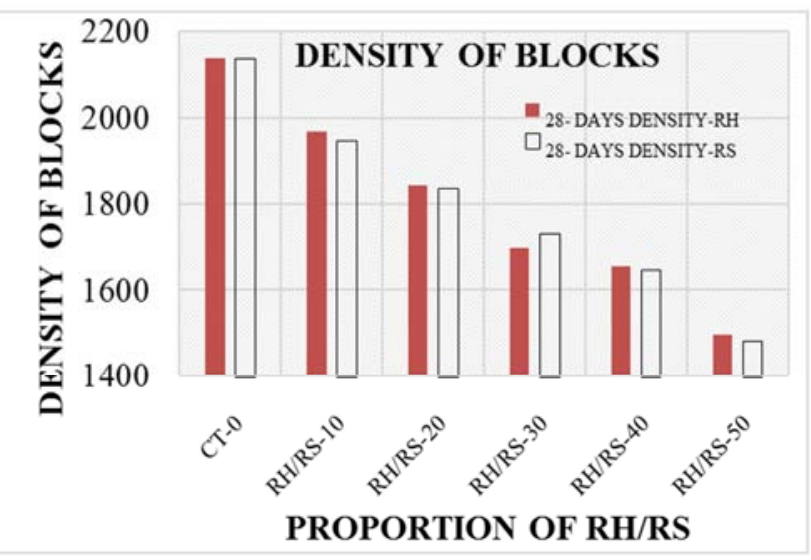

Figure 4. Relationship between fibre proportion and densities of blocks.

Figure 4 indicates an inverse or negative linear relationship between the densities of the blocks and the proportions of $\mathrm{RH} / \mathrm{RS}$ in the blocks. This indicates that addition of $\mathrm{RH}$ and RS leads to reduction in the densities of the blocks. This indicates effectiveness of $\mathrm{RH} / \mathrm{RS}$ in making lightweight fibrecrete blocks.

The reduction in the densities was attributed to incorporation of RH/RS in the blocks as the fibres have low densities of between 331.59-380.54 Kg/m ${ }^{3}$ and $162.03-194.48 \mathrm{Kg} / \mathrm{m}^{3}$ for rice husks and straws respectively [33]. The low density of the blocks was also attributed to the void created in the blocks as revealed by the microstructure of the blocks as in Figure 6 and Figure 8.

\subsection{Compressive Strength}

The compressive strength of RH/RS blocks presented in Table 2 show a reduction in the compressive strength with increase in proportion of the fibre. This effect was greatly noticed with the RS blocks, showing RH blocks have higher compressive strength compared to RS blocks.
Table 2. Compressive Strength of the blocks.

\begin{tabular}{lllllll}
\hline Curing Period & \multicolumn{7}{l}{ Compressive Strength $\left(\mathbf{N} / \mathbf{m m}^{\mathbf{2}}\right)$} \\
\hline \multirow{3}{*}{ 7-Days } & CT-0 & RH-10 & RH-20 & RH-30 & RH-40 & RH-50 \\
28-Days & 4.75 & 3.45 & 2.79 & 1.93 & 1.76 & 0.98 \\
& 6.89 & 5.36 & 4.29 & 3.35 & 2.64 & 1.53 \\
& CT-0 & RS-10 & RS-20 & RS-30 & RS-40 & RS-50 \\
2-Days & 4.75 & 1.72 & 0.90 & 0.83 & 0.63 & 0.5 \\
\hline
\end{tabular}

Compressive strength of $\mathrm{RH}$ blocks ranged between $1.53 \mathrm{~N} / \mathrm{mm}^{2}$ for RH-50 and $5.36 \mathrm{~N} / \mathrm{mm}^{2}$ for RH-10 while the values for RS-50 and RS-10 were $1.28 \mathrm{~N} / \mathrm{mm}^{2}$ and $3.48 \mathrm{~N} / \mathrm{mm}^{2}$ respectively at 28 days.

According to (ASTM C-129, 2011), the minimum compressive strength of blocks is $3.45 \mathrm{Mpa}\left(\mathrm{N} / \mathrm{mm}^{2}\right)$ for the individual blocks and $4.14 \mathrm{Mpa}\left(\mathrm{N} / \mathrm{mm}^{2}\right)$ for average of three blocks. On the other hand standard specification for building works of Uganda 2012, the minimum compressive strength of blocks is $2.2 \mathrm{Mpa}\left(\mathrm{N} / \mathrm{mm}^{2}\right)$ for the individual blocks and 2.8 $\mathrm{Mpa}\left(\mathrm{N} / \mathrm{mm}^{2}\right)$ for average of 10 (ten) blocks. This implies that; blocks of RH10 - RH 40 and RS 10 -RS 20 satisfy the strength requirements as per Ugandan standard specification.

\subsection{Water Absorption}

Table 3. Water absorption of RH/RS blocks.

\begin{tabular}{lllllll}
\hline \multicolumn{7}{c}{ Water absorption (\%) } \\
\hline \multirow{2}{*}{ RH-Blocks } & CT-0 & RH-10 & RH-20 & RH-30 & RH-40 & RH-50 \\
& 3.6 & 5.8 & 6.2 & 6.4 & 7.4 & 7.6 \\
\multirow{2}{*}{ RH-Blocks } & CT-0 & RS-10 & RS-20 & RS-30 & RS-40 & RS-50 \\
& 3.6 & 6.4 & 7.5 & 8.3 & 9.3 & 11.3 \\
\hline
\end{tabular}

According to Uganda standard specifications for building works, the maximum water absorption of blocks depends on the density of the blocks (density grade). For grade A blocks whose density $\geq 2100 \mathrm{Kg} / \mathrm{m}^{3}$, the maximum water absorption is $11 \%$; Grade $\mathrm{B}$, where $1681 \mathrm{Kg} / \mathrm{m}^{3} \leq$ density $\leq 2099 \mathrm{Kg} / \mathrm{m}^{3}$, the maximum water absorption is $13 \%$; Grade $\mathrm{C}$, where density $\leq 1680 \mathrm{Kg} / \mathrm{m}^{3}$, the maximum water absorption of $17 \%$.

As per Table 3 and Figure 4, the water absorption for grade $\mathrm{B}$ blocks is less than $13 \%$ (maximum water absorption for grade $\mathrm{B}$ blocks) and water absorption for grade $\mathrm{C}$ blocks is less than $17 \%$ (maximum water absorption for grade $\mathrm{C}$ blocks). Similarly, as per ASTM C90-11b, the maximum acceptable value of water absorption in masonry blocks is $12 \%$, and this condition was satisfied by all the RH/RS blocks.

\subsection{Thermal Conductivity}

Table 4. Thermal Conductivity of RH/RS blocks.

\begin{tabular}{lllllll}
\hline \multicolumn{7}{c}{ Thermal Conductivity (w/mk) } \\
\hline \multirow{3}{*}{ RH-Block } & CT-0 & RH-10 & RH-20 & RH-30 & RH-40 & RH-50 \\
& 1.0059 & 0.7117 & 0.6378 & 0.5190 & 0.4404 & 0.3542 \\
& CT-0 & RS-10 & RS-20 & RS-30 & RS-40 & RS-50 \\
RS-Block & 1.0059 & 0.8710 & 0.8289 & 0.6356 & 0.4597 & 0.3559 \\
\hline
\end{tabular}

The thermal conductivity of the fibrecrete blocks were tested to measure the thermal insulation capacity of the blocks when used for walling. From Table 4, it was observed that, the 
thermal conductivity of the blocks decreased as the proportion of the RH/RS increased. The thermal conductivity ranged between $0.3542 \mathrm{w} / \mathrm{mk}$ for RH-50 blocks and $0.7117 \mathrm{w} / \mathrm{mk}$ for RH-10 blocks respectively while the thermal conductivity values for RS blocks ranged between $0.3559 \mathrm{w} / \mathrm{mk}$ for RS- 50 blocks and $0.8710 \mathrm{w} / \mathrm{mk}$ for RS-10 blocks. These values of thermal conductivity are less than that of the control/aggregate blocks ( $1.0059 \mathrm{w} / \mathrm{mk})$; thus indicating that $\mathrm{RH} / \mathrm{RS}$ blocks can transfer less heat per unit time as compared to the control blocks. This indicates that fibrecrete blocks have good thermal insulation property.

In general, thermal conductivity is an important aspect in buildings. The understanding regarding heat transfer and temperature distribution through the building material can be used for analysis of the energy use and thermal comfort of the building. Good thermal insulation provides thermal comfort without excess air conditioning, which is one of the primary requirements of a building.

\subsection{Fire Resistance}

Table 5. Residual compressive strength of fired RH/RS blocks.

\begin{tabular}{lllllll}
\hline \multicolumn{7}{c}{ Residual Compressive Strength (N/mm $\mathbf{m}^{\mathbf{2}}$} \\
\hline \multirow{3}{*}{ 28- Days } & CT-0 & RH-10 & RH-20 & RH-30 & RH-40 & RH-50 \\
& 5.61 & 4.74 & 3.43 & 1.85 & 1.61 & 1.01 \\
& CT-0 & RS-10 & RS-20 & RS-30 & RS-40 & RS-50 \\
\hline
\end{tabular}

The residual compressive strength of the fired blocks as in Table 5 indicate a general reduction in strength as compared to unfired blocks. The percentage loss in the compressive strength of the blocks increased with increase in the proportion of the fibre in the blocks. The values of strength loss ranged between $10.7 \%$ for RH-10 blocks and $34.3 \%$ for RH-50 blocks. The corresponding value for RS blocks were $6.8 \%$ for RS-10 to $73.7 \%$ for RS-50. This shows that the quantity of the fibres in the fibrecrete blocks caused the reduction in the compressive strength of the blocks. This was attributed to combustion of the fibres during firing. However, the residual compressive strength of RH-10, RH-20 and RS-10 blocks still satisfy the minimum compressive strength of $2.2 \mathrm{~N} / \mathrm{mm}^{2}$ as per standard specification for building works of Uganda 2012.

\subsection{Microstructure of the Block}

The different microstructures shown in Figure 5 Control blocks without cracks and voids, Figure 6 Rice straw blocks with voids surrounding the straws, Figure 7 Rice straw blocks with micro cracks, Figure 8 Rice husk blocks with voids surrounding the straws. Figure 6, Figure 7 and Figure 8 indicate that, the blocks have voids around the husks and straws and development of micro cracks in the blocks. These voids in the blocks explain their better thermal insulation and their reduced density, compressive strength and fire resistance.

The development of micro cracks in the blocks could be due to volume change of the fibre in the blocks as uniform volume changes in the control blocks do not produce cracking if the element or structure is relatively free to change volume in all directions. The volume changes are more in the fibrecrete blocks due to increases water absorption of RS and RH blocks as compared to the control blocks.

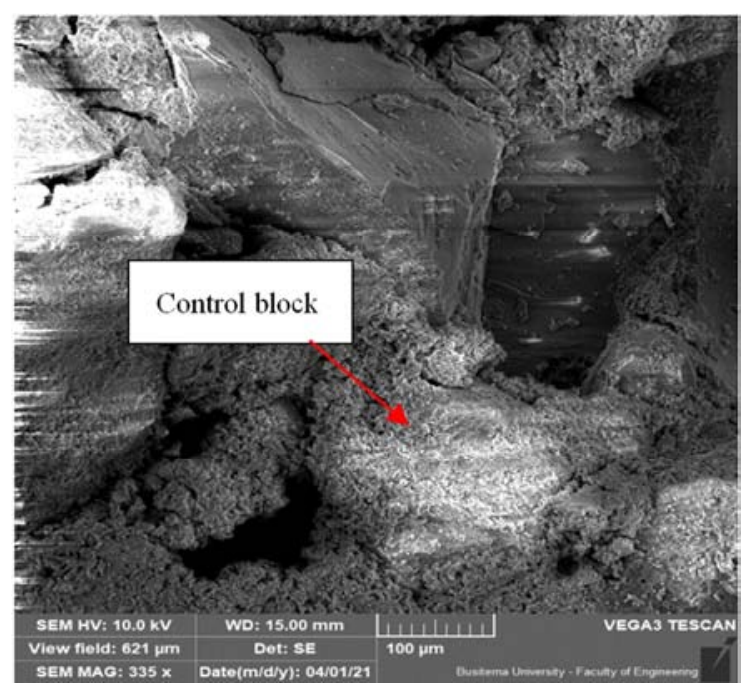

Figure 5. Control blocks without voids and cracks.

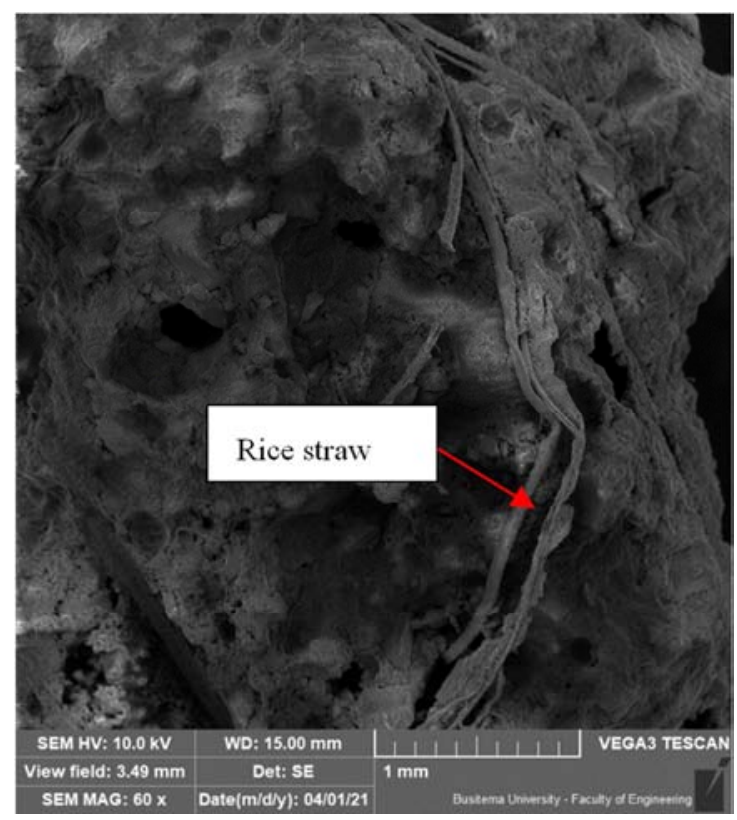

Figure 6. Rice straw blocks with void surrounding the straws.

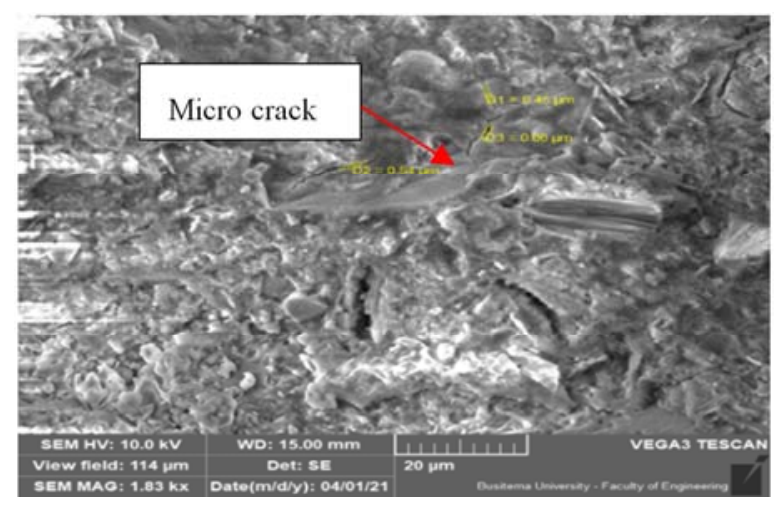

Figure 7. Rice straw blocks with micro cracks. 


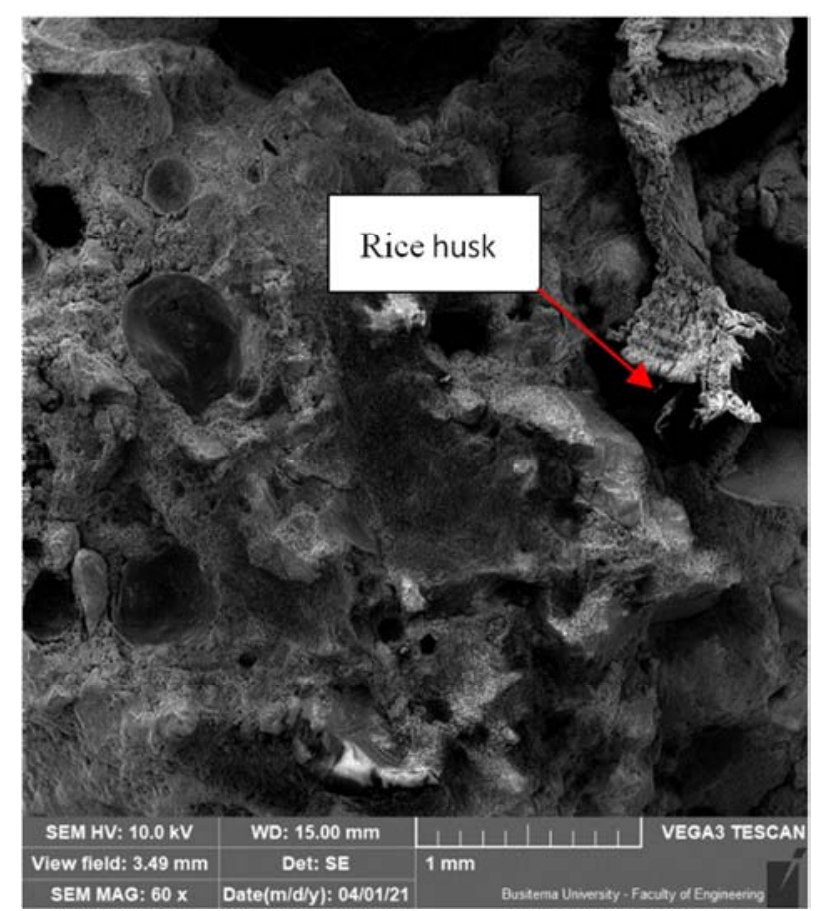

Figure 8. Rice husk block with voids surrounding the husks.

\section{Conclusions and Recommendations}

\subsection{Conclusion}

The study concluded that, RH-40 and RS-20 blocks have the most appropriate proportions for lightweight fibrecrete blocks for walling, as these proportions meet the minimum compressive strength requirements as per Ugandan standard specifications.

The study concluded that, the use of rice husks and rice straws in lightweight fibrecrete blocks improved the properties of concrete blocks. This lead to reduction in the density of blocks, reduced thermal conductivity hence increased thermal insulation; reduced fire resistance and compressive strength and increased water absorption.

The study concluded that, the use of rice husks and straws in lightweight fibrecrete blocks would reduce on the Environmental degradation, utilize agricultural waste, increase the income of the farmers and reduce the cost of construction.

\subsection{Recommendation}

Although the water absorption of the blocks were within the recommended limits as per Uganda standard specifications. Due to the effect of wetting and drying of the blocks, that causes volume changes in the fibres within the block, this can lead to development of micro-cracks in the blocks, the researcher therefore recommend that, these blocks be used for internal walling that is less susceptible to moisture.

The study recommended further studies on ways of improving the fire resistance of light weight fibrecrete blocks by use of appropriate fire retarders in order to have adequate resistance in case of fire outbreak without compromising other properties of the blocks.

\section{Acknowledgements}

The author would like to thank the staff of Kyambogo University for their guidance and support during the course of the study and research.

\section{References}

[1] Uganda Bureau of Statistics., 2002. Uganda population and Housing Census: Analytical report: A bridged version: Uganda Bureau of Statistics.

[2] Uganda Bureau of Statistics., 2010. Statistical abstract: Analytical report: A bridged version: Uganda Bureau of Statistics.

[3] Malik, K., 2014. Human development report: Sustaining human progress: Reducing vulnerabilities and building resilience, New York: United Nations Development Programme.

[4] Alinaitwe, H., Mwakali, J., Hansson, B., 2006. Assessing the degree of industrialisation in construction - A case of Uganda. Journal of Civil Engineering and Management, Vol XII (3), pp. 221-229.

[5] Uganda Bureau of Statistics., 2017. Statistical abstract: Analytical report: A bridged version: Uganda Bureau of Statistics.

[6] Mishra, S. \& Usmani, J., 2013. Comparison of embodied energy in different masonry wall materials. International Journal of Advanced Engineering Technology, 4 (4), pp. 90-92.

[7] Ministry of Lands, Housing and Urban Development., 2016: Sector Perfomance Report of Lands, Housing and Urban Development: financial year 2014-2015 report.

[8] Pérez-Peña, A., 2009. Interlocking Stabilised Soil Blocks: Appropriate Earth Technologies in Uganda,: UN-HABITAT.

[9] Nationsl Environmental Management Authority., 2008. National implementation plan of stockholm convention on persistent organic pollutants for Uganda.

[10] Mostafa., M. \& Uddin, N., 2015. Effect of banana fibers on the compressive and flexural strength of compressed earth blocks. Buildings, 5 (1), pp. 282-296.

[11] UN-HABITAT., 2012., United Nations Human Settlement Programme (UN-Habitat) -Annually Report.

[12] Danso, H., Martinson, D., Ali, M. \& William., 2015. Effect of fibre aspect ratio on mechanical properties of soil building. Construction and Building Materials, Volume 83, pp. 314-319.

[13] Madurwar., 2013. Application of agro-waste for sustainable construction materials. A review Construction and Building Materials., Volume 38, pp. 872-878.

[14] Gunduz., 2007. use of quartet blend containing fly ash, scoria, perlitic pumice and cement to produce cellular hollow light weight mosonry blocks for non load bearing walls. construction and building materials, 22 (5), pp. 747-754. 
[15] Amato, G; Cambione, G; Cavaleri, L; Minato, G; Miraghi, N., 2011. The use of pumice light weight concrete for masonry application.

[16] Hashemi, A., Cruickshank, H., Cheshmehzangi, A., 2015. Environmental impacts and embodied energy of construction methods and materials in low-income tropical housing. Sustainability, 7 (6), pp. 7866-7883.

[17] Uganda Bureau of Statistics., 2019. Statistical abstract: Analytical report: A bridged version: Uganda Bureau of Statistics.

[18] Pacheco-Torgal, F. \& Jalali, S., 2011a. Cementitious building materials reinforced with vegetable fibres. Construction and Building Materials, 25 (2), pp. 575-581.

[19] Girijappa, Y., Gowda, T., Suchart, S. \& Rangappa, S. M., 2019. Natural Fibers as Sustainable and Renewable Resource for Development of Eco-Friendly Composites. Comprehensive Review., 6 (22).

[20] Ajouguim, Soukaina; Stefanidoub, Maria; Abdelouahdi, Karima; Waqif, Mohamed; Latifa, Saâdi., 2020. Influence of treated bio-fibers on the mechanical and physical properties of cement mortars. European Journal of Environmental and Civil Engineering.

[21] Susheel, K., Kaith, B. \& Kaur, I., 2009. Pretreatments of Natural Fibers and their Application as Reinforcing Material in Polymer Composites -A Review.

[22] Santos, S. F. D; Tonoli, G, H, D; Mejia, J, E, B; Fiorelli, J; Savastano Jr, H., 2015. Non-conventional cement-based composites reinforced with vegetable fibers. A review of strategies to improve durability. Materials of Construction, 65 (317), p. 041.

[23] Wang, B., Panigrahi, S., Tabil, L. \& Crerar, A., 2007. Pre-treatment of Flax Fibers for use in Rotationally Molded Biocomposites. Journal of reinforced plastics and composites, $26(5)$.

[24] Onuaguluchi, O. \& Banthia, N., 2016. Plant-based natural fibre reinforced cement composites: A review. Cement and Concrete Composites, Volume 68, pp. 96-108.
[25] Parveen, S., Rana, S. \& Fangueiro, R., 2017. Macro- and nanodimensional plant fiber reinforcements for cementitious composites. Sustainable and Nonconventional Construction Materials using Inorganic Bonded Fiber Composites, pp. 343-382.

[26] Kabir, M., Wang, H. \& Aravinthan, T., 2011. Effects of natural fibre surface on composite properties. A review. Proceedings of the 1st international post graduare conference on engineering, designing and developing the built environment for sustainable well being (eddBE2011); pp. 94-99.

[27] Bachir, T. \& Abdelhamid, G., 2016. The mechanical and physical properties of compressed earth block stabilized with lime and filled with untreated and alkali-treated date palm fibers. Construction and Building Materials, Volume 104, p. $52-62$.

[28] Hashim, Mohd Yussni, Azriszul, Mohd Amin; Faizan Marwah, Omar Mohd; Mohd Hilmi, Othman; Mohd Radzi, Moham., 2017. The effect of alkali treatment under various conditions on physical properties of kenaf fiber., IOP Publishing Ltd.

[29] Ajouguim, Soukaina; Abdelouahdi, Karima; Waqif, Mohamed; Maria, Stefanidou; Latifa, Saadi., 2019. Modifications of Alfa fibers by alkali and hydrothermal treatment. Cellulose, 26, pp. 1503-1516.

[30] Machaka, M., Basha, H., Chakra, H. A. \& Elkordi, A., 2014. Alkali treatment of fan palm natural fibre for use in fibre reinforced concrete. European Scientific Journal, 10 (12), pp. 186-195.

[31] Sedan, D., Pagnoux, C., Smith, A. \& Chotard, T., 2008. Mechanical properties of hemp fibre reinforced cement: Influence of the fibre/matrix interaction. Journal of the European Ceramic Society, 28 (1), pp. 183-192.

[32] Akil, H., Omar, H., Mazuki, M. F., Safiee, A., 2011. Kenaf fiber reinforced composites:. A review. materials \& design, 32 (8-9), pp. 4107-4121.

[33] Zhang, Y., Ghaly, A., Bingxi, L., 2012. Physical properties of rice residues as affected by variety and climatic and cultivation conditions in three continents. American Journal of Applied Sciences, 9 (11), pp. 1757-1768. 